\title{
Pengaruh Bakat Numerikal Terhadap Prestasi Belajar Siswa Sekolah Menegah Atas
}

\author{
Susana Tualena \\ Program Studi Bimbingan dan Konseling, Universitas Pattimura, Indonesia \\ susanatualena@gmail.com
}

\begin{tabular}{c|c|c}
\hline Diterima: Oktober 2020 & Disetujui: November 2020 & Dipublikasi: November 2020 \\
\hline
\end{tabular}

\begin{abstract}
Abstrak
Sekolah Menengah Atas Negeri 4 Ambon memiliki Jumlah siswa kelas X sebanyak 365 orang dan kelas X-8 berjumlah 29 orang. Ada sebagian Siswa kelas X-8 yang memiliki Prestasi Belajar yang rendah atau tidak mencapai KKM yaitu 75. Prestasi Belajar yang rendah dipengaruhui oleh beberapa faktor salah satunya adalah bakat akademik yaitu bakat numerikal atau kemampuan memahami konsep yang berkaitan dengan angka-angka. Penelitian ini bertujuan untuk mengetahui Pengaruh Bakat Numerikal Terhadap Prestasi belajar Siswa Kelas X (Sepuluh). Populasi pada penelitian ini adalah kelas $\mathrm{X}$ yang berjumlah 365 orang dan dipilih sebagai sampel secara teknik sampling purposive. Sampling purposive adalah teknik pengambilan sampel atas pertimbangan tertentu, yang berjumlah 29 orang. Pengumpulan data dilakukan dengan tes tertulis kemampuan numerikal yaitu Tes Differential Aptitude Test (DAT), dan pendataan nilai prestasi belajar dari rapot semester ganjil-genap. Pengujian data dilakukan dengan menggunakan analisis regresi linear sederhana dan selanjutnya menggunakan program komputer SPSS - 20. Hasil penelitian dengan persamaan regresi $: \hat{Y}=\beta+(b 1 . X 1)$ Prestasi belajar matematika $=8,084+(2.549 \times \mathrm{X} 1)$ antara kemampuan numerikal mempunyai pengaruh yang signifikan terhadap prestasi belajar karena mempunyai nilai Thitung (17.4422) > Ttabel (1.699) dengan taraf signifikansi 0.05. ini berarti Hipotesa H0 ditolak dan Ha diterima artinya variabel bakat numerikal memiliki pengaruh yang signifikan terhadap prestasi belajar.
\end{abstract}

Kata Kunci: Bakat Numerikal, Prestasi Belajar

\begin{abstract}
This SMA N 4 Ambon has 365 class X students and 29 X-8 class students. There are some students in class X-8 who have low Learning Achievement or do not reach the $K K M$, namely 75. Low learning achievement is influenced by several factors, one of which is academic talent, namely numerical aptitude or the ability to understand concepts related to numbers. This study aims to determine the effect of numerical talent on learning achievement of class $X$ (Ten) students. The population in this study was class $X$ totaling 365 people and was selected as a sample by purposive sampling technique. Purposive sampling is a sampling technique based on certain considerations, amounting to 29 people. The data was collected by means of a written numerical ability test, namely the Differential Aptitude Test (DAT), and data collection on achievement scores from the odd-even semester report cards. Data testing was performed using simple linear regression analysis and then using the SPSS-20 computer program. The results of the study with the regression equation: $Y=\beta+(b 1 . X 1)$ learning achievement $=8,084+(2,549 \times \mathrm{X1})$ between numerical abilities has a significant influence significant towards learning achievement because it has a value of t (17.4422)> t table (1.699) with a significance level of 0.05. This means that the hypothesis HO is rejected and $\mathrm{Ha}$ is accepted, it means that the numerical aptitude variable has a significant effect on learning achievement.
\end{abstract}

Keywords: Numerical Aptitude, Learning Achievement 


\section{PENDAHULUAN}

Sekolah sebagai lembaga Pendidikan formal mempunyai tanggungjawab besar dalam mengsukseskan peserta didik. Selain itu juga sekolah merupakan tempat yang tepat untuk mengali dan mengembangkan bakat (aptitude) peserta didik, karena sekolah memiliki sistem yang kompleks dan dinamis, dalam kegiataannya. Dengan demikian dapat dikatakan bahwa tanpa sekolah sesungguhnya tidak akan ada proses belajar mengajar antara Guru dan Murid. Oleh sebab itu pentingnya sekolah sebagai wadah yang dapat mempersiapkan, membentuk dan melahirkan kader-kader bangsa yang mengharumkan nama bangsa melalui potensi yang dimiliki.

Sekolah memiliki peran penuh dalam menjalankan tugas pokok dan fungsi sekolah yaitu meneruskan, mempertahankan dan mengembangkan kebudayaan masyarakat hal ini di lakukan melalui pembentukan kepribadian peserta didik dengan memberikan ilmu pengetahuan dan penanaman nilai-nilai yang mendukung pembentukan kepribadian dengan tujuan agar peserta didik menjadi dewasa dari sudut usia dan intelektualnya selain itu agar mereka terampil dan bertanggungjawab sebagai upaya mempersiapkan generasi penganti yang mampu mempertahankan eksistensi kelompok atau masyarakat bangsa dengan budaya yang mendukung karena itu sekolah merupakan satuan pendidikan terdepan dalam mendidik peserta didik serta memerlukan pengelolaan yang profesional yang berlandaskan pada fungsi tugasnya.

Layanan Bimbingan dan Konseling disekolah sangat diperlukan karena pelayanan Bimbingan dan Konseling merupakan usaha membantu peserta didik dalam pengembangan kehidupan pribadi, kehidupan sosial, kegiatan belajar, serta perencanaan dan pengembangan karier. Pelayanan bimbingan dan konseling juga menfasilitasi pengembangan peserta didik, secara individual, kelompok, dan klasikal sesuai kebutuhan, potensi, bakat, minat, perkembangan, kondisi, serta peluang-peluang yang dimiliki.

Kementerian Kebudayaan Pendidikan Dasar Menengah melakukan pengembangan kurikulum menjadi Kurikulum 2013. Pengembangan kurikulum 2013, dirancang untuk mempersiapkan insan Indonesia yang memiliki kemampuan hidup sebagai pribadi dan warga negara yang produktif, kreatif, inovatif, dan afektif serta mampu berkontribusi pada kehidupan bermasyarakat, berbangsa, bernegara dan peradaban dunia. Kurikulum 2013 memberikan kesempatan kepada peserta didik untuk mengembangkan kemampuan, bakat dan minat secara lebih luas dan terbuka sesuai dengan prinsip perbedaan individu. Ini memungkinkan peserta didik berkembang over achievement, yakni peserta didik yang memiliki tingkat penguasaan di atas standar yang telah ditentukan baik dalam pengetahuan, sikap, maupun keterampilan.

Proses pengembangan kemampuan, bakat, dan minat merupakan indikator pencapaian keberhasilan sekolah dalam mengembangkan tugasnya, dapat dilihat dari pencapaian prestasi yang tinggi. Menurut Suryabrata (1998), Prestasi akademik adalah istilah yang menunjukan derajat keberhasilan siswa dalam mencapai tujuan belajar, setelah melakukan proses belajar dari suatu program yang telah ditentukan atau berkaitan dengan penguasaan pengetahuan atau ketrampilan yang dikembangkan melalui mata pelajaran. Dengan demikian dapat dikatakan bahwa Siswa yang berhasil atau berprestasi dalam mata pelajaran apabila memperoleh standar nilai yang merupakan 
akumulasi dari aspek pengetahuan, keterampilan dan sikap. Keberhasilan siswa di kelas tercermin dalam aspek pengetahuan yang telah diterimanya ketika proses belajar mengajar.

Penilaiaan terhadap hasil belajar yang diperoleh siswa, maka setiap sekolah tentu memiliki Kriteria Ketuntasan Minimal (KKM) yang berbeda-beda. Hal ini tergantung pada kompleksitas, daya dukung, dan intake peserta didik. Disamping itu KKM digunakan sebagai acuan untuk menyatakan peserta didik tuntas dalam mengikuti pembelajaran. Sehubungan dengan hal tersebut Sekolah Menengah Atas Negeri 4 Ambon memiliki standar KKM yaitu, 75 untuk semua mata pelajaran, hal ini diharapkan agar siswa lebih meningkatkan motivasi belajar baik di sekolah maupun dirumah. Standar KKM juga merupakan aspek penilaian tentang berhasil atau tidaknya pencapaiaan ketuntasaan belajar baik secara tertulis atau lisan.

Hasil observasi dan wawancara peneliti saat Kuliah Kerja Nyata dan Penelitian Praktek lapangan di Sekolah Menengah Atas Negeri 4 Ambon diperoleh informasi dari Guru BK dan Guru Mata pelajaran bahwa motivasi belajar siswa-siswi rata-rata tidak mencapai KKM, hal ini terlihat pada siswa kelas X8 dalam proses belajar mengajar untuk penguasaan materi hanya 50\% sedangkan dari 36 orang untuk ulangan harian pertama (I) semuanya dibawah rata-rata yang berkisar 5-55, ulangan harian kedua (II) yaitu 20-70, dan untuk nilai MID 14 orang yang mencapai KKM yaitu 75-80 sedangkan untuk nilai UAS semuanya dibawah rata-rata yang berkisar 20-73,33. Di samping itu semua siswa mengikuti remedial karena tidak mencapai KKM.

Sebagai calon Guru Bimbingan dan Konseling, Peneliti tertarik untuk memberikan tes bakat sebagai data yang dapat digunakan oleh Guru BK, Guru Mata Pelajaran, Wali Kelas dan Siswa. Dalam hal ini Guru Bimbingan dan Konseling akan lebih mudah untuk menetapkan dan menyalurkan siswa berdasarkan hasil yang diperoleh baik dari, Guru mata pelajaran dalam proses belajar mengajar akan lebih membangun interaksi edukatif yang baik di kelas, wali kelas akan memperhatikan kinerja siswa di dalam kelas, siswa akan mengenal secara baik potensi yang dimiliki.

Tes bakat yang digunakan yaitu DAT yang mana terdiri atas delapan macam subtes, Yaitu berpikir verbal (verbal Reasoning), Kemampuan numerical (Numerical Ability), Kecepatan dan ketelitian Klerikal (Clerical SpeedRelations), Pemakaian Bahasa I (Language Usage I), Pemakaian Bahasa II (Language Usage II). Namun tes bakat yang akan peneliti berikan hanya terpusat pada tes bakat numerical. Tes bakat numerical yaitu tes yang dirancang untuk melihat seberapa baik seseorang dapat mengerti ide-ide dan konsep-konsep yang dinyatakan dalam bentuk angka-angka. Juga untuk melihat seberapa mudah seseorang dapat berpikir dan memecahkan masalah-masalah yang dinyatakan dalam bentuk angka-angka (Hukubun,N. Resley, I \& Arjanto, P.2015). Pemberian tes dilakukan untuk mengetahui kemampuan seseorang dalam menguasai suatu bidang tertentu peneliti menggunakan tes bakat dengan tujuan untuk membantu dan memberikan gambaran mengenai kemampuan seseorang di berbagai area.

Olehnya itu Lembaga Pendidikan atau sekolah merupakan salah satu sarana untuk mendidik anak menjadi seseorang yang bisa mengembangkan bakat numeriknya, karena termasuk dalam bakat akademik salah satunya adalah bakat numerik atau 
kemampuan memahami konsep yang berkaitan dengan angka-angka (Ali \& Asrori, 2005). Berdasarkan uraikan tersebut, maka penelitian ini bertujuan menganalisis pengaruh bakat numerikal terhadap prestasi belajar siswa pada Sekolah Menengah Atas Negeri 4 Ambon

\section{METODE}

Dalam penelitian ini digunakan pendekatan kuantitatif untuk mengukur bakat dan hasil belajar siswa SMA Negeri 4 Ambon Kelas X. Populasi dalam penelitian ini berjumlah 365. Teknik pengambilan sampel menggunakan purposive sampling. Subjek penelitian yang dipakai dalam penelitian ini yaitu keseluruhan siswa kelas X.8 yang berjumlah 29 orang. Data tes bakat siswa diperoleh dengan menggunakan instrumen tes Bakat Differential Aptitude Test (DAT). Sedangkan untuk hasil belajar yakni difokuskan kepada hasil belajar matematika dilihat dari nilai ujian akhir siswa. Analisis data menggunakan uji linear sederhana.

\section{HASIL TEMUAN}

\section{Hasil Tes Bakat}

Tes Bakat diikuti oleh 29 Siswa dari kelas X8 SMA Negeri 4 Ambon. Berikut hasil tes bakat numerikal dapat dilihat pada tabel 1:

Tabel 1.Persentase Tes Bakat Numerikal Berdasarkan Kategorisasi dan Frekuensi

\begin{tabular}{llll}
\hline No & Kategorisasi & Frekuensi & Persentase \\
\hline 1. & Bakat Rendah & 26 & $89,7 \%$ \\
2. & Bakat Sedang & 2 & $6,9 \%$ \\
3. & Bakat Tinggi & 1 & $3,4 \%$ \\
\hline & Jumlah & 29 & $100 \%$ \\
\hline
\end{tabular}

Berdasarkan tabel 1 Persentase Tes bakat numerikal terlihat jelas bahwa ada siswa yang memiliki bakat, tinggi, sedang dan rendah. Artinya bahwa dari 29 siswa yang mengikuti tes bakat numerikal dapat dilihat hasil bahwa ada siswa yang memiliki bakat numerikal dan juga tidak memiliki bakat numerikal. Hal ini menunjukan bahwa ada peluang untuk sebagian siswa tersebut dapat mengembangkan bakatnya. Disamping itu bagi siswa yang memiliki bakat rendah pada bakat numerikal kemungkinan memiliki bakat yang lain dari bakat ini.

\section{Hasil Prestasi Belajar Sis wa}

Berikut hasil pengukuran prestasi belajar siswa dari kelas X8 SMA Negeri 4 Ambon yang dapat dilihat pada tabel 2 di bawah ini :

Tabel 2 Hasil Prestasi Belajar Sis wa Berdasarkan Kategorisasi dan Frekuensi

\begin{tabular}{ccccc}
\hline No & Kategorisasi & Frekuensi & $\begin{array}{c}\text { Rata-rata Nilai UAS } \\
\text { yang dipe roleh }\end{array}$ & Keterangan \\
\hline 1. & Nilai Terendah & 20 & $13-46$ & Tidak Tuntas \\
2. & Nilai Sedang & 8 & $50-63$ & Tidak Tuntas \\
3. & Nilai Tertinggi & 1 & 73 & Tidak Tuntas \\
\hline & Jumlah & 29 & & Tidak Tuntas \\
\hline
\end{tabular}


Berdasarkan hasil tabel 2 yang menunjukan bahwa dari, 29 siswa rata-rata tidak mencapai Kriteria Ketuntasan Minimal (KKM), memang ada sebagian siswa yang memilki nilai hampir mendekati nilai KKM yaitu 75 yang dikategori sebagai nilai tertinggi yaitu 1 orang, nilai sedang 8 orang dan nilai terendah yaitu 20 orang. Dengan demikian hasil prestasi belajar siswa kelas X8 menunjuikan bahwa $100 \%$ semuanya tidak tuntas artinya bahwa rata-rata semuanya tidak mencapai KKM atau Kriteria Ketuntasan Minimal.

Pengaruh Bakat Nume rikal Terhadap Prestasi Belajar Sis wa

Berdasarkan hasil tes bakat numerikal dan prestasi belajar siswa, maka peneliti melakukan analisis lanjutan dengan menggunakan SPSS 20.0 pada persamaan regresi linear sederhana dengan hasil yang didapat pada Tabel 3 sebagai berikut.

Tabel 3 Regresi Linear sederhana Pengaruh Bakat Numerikal Terhadap Pres tasi Belajar

\begin{tabular}{cccccc}
\hline Model & R & $\begin{array}{c}\text { R } \\
\text { Square }\end{array}$ & $\begin{array}{c}\text { Adjusted } \\
\text { R Square }\end{array}$ & $\begin{array}{c}\text { Std. Error of the } \\
\text { Estimate }\end{array}$ & Durbin-Watson \\
\hline 1 & $.895^{\mathrm{a}}$ & .801 & .915 & 4.387 & 2.107 \\
\hline
\end{tabular}

Berdasarkan Tabel 3 terlihat bahwa Angka $\mathrm{R}$ sebesar $.895^{\mathrm{a}}$ menunjukan bahwa korelasi atau hubungan antara prestasi belajar dengan bakat numerikal adalah kuat. Korelasi antara prestasi belajar dan bakat numerikal bersifat positif artinya jika bakat numerikal naik maka akan direspon dengan kenaikan prestasi belajar. Nilai $\mathrm{R}^{2}$ ( $\mathrm{R}$ Square) atau Koefisien Determinasi adalah .801 hal ini berarti 80,1\% variasi dari prestasi belajar dapat dijelaskan oleh variasi dari bakat numerikal. Sedangkan sisanya (100\% $80,1 \%=19,9 \%$ ) dijelaskan oleh sebab-sebab yang lain misalnya kurangnya kesiapan dalam mengikuti UAS, kurangnya, konsentrasi dalam proses belajar mengajar, sering tidak masuk sekolah dan lain-lain. Sedangkan Nilai uji statistik Durbin-Watson $=2.107$, jadi dapat dipastikan tidak terjadi autocorrelation. Standard Error of Estimate (SEE) adalah 4.387 semakin kecil SEE akan membuat model regresi semakin tepat dalam memprediksi variabel dependent.

\section{PEMBAHASAN}

Dari deskripsi data dan analisis uji yang telah dilakukan diketahui bahwa terdapat Besarnya pengaruh bakat numerikal terhadap prestasi belajar sebesar 80,1\% sedangkan sisanya sebesar 19,9\% yang dipengaruhui oleh faktor lain, seperti ketidaksiapan siswa dalam mengikuti UAS, Kurangnya konsentrasi dalam proses belajar mengajar, sering tidak masuk sekolah dan lain-lain. Data ini diperoleh dari wawancara langsung dengan Guru Mata pelajaran juga beberapa siswa yang memiliki bakat tinggi dan sedang pada tes bakat numerikal. Dari uji ANOVA atau F test, didapat F hitung adalah 304.212 dengan tingkat signifikansi "0.000. karena probabilitas (0.000) jauh lebih kecil dari 0.05 maka model regresi bisa dipakai untuk memprediksi $\mathrm{Y}$.

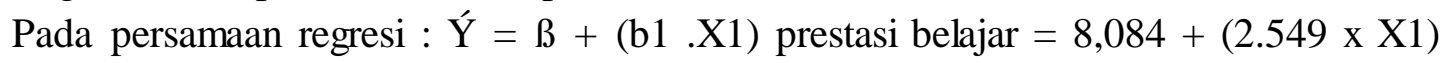
Konstanta sebesar 8.084, Koefisien regresi 2.549 menyatakan bahwa setiap penambahan "1 nilai bakat numerikal akan meningkatkan/mengurangi "prestasi belajar" sebesar .958 dengan tingkat signifikansi " $0,000 "$ dan untuk menguji signifikansi masing-masing 
koefisien regresi gunakan uji $\mathrm{T}$ (t-hitung $=17.442$ ) jika dibandingkan dengan $\mathrm{t}$-Tabel yaitu (1.699) maka $\mathrm{T}$ hitung $>\mathrm{T}$ tabel (17.442>1.699) oleh sebab itu Hipotesis : Ho : koefisien regresi tidak signifikan sedangkan $\mathrm{Ha}$ : koefisien regresi signifikan. Hal ini terlihat dari jika probabilitas > 0.05, maka Ho diterima dan Jika probabilitas < 0.05, maka Ho ditolak.

Dengan demikian Berdasarkan kolom sig variabel bakat numerikal, memiliki taraf signifikan < 0.05 yaitu 0.000 , artinya variabel bakat numerikal memiliki pengaruh yang signifikan terhadap prestasi belajar. Menurut teori, kemampuan numerik yang tinggi dan prestasi belajar yang baik, maka peserta didik akan dapat mencapai keberhasilan yang baik pula. Karena pada dasarnya keduanya memilki tujuan yang sama yaitu hasil yang ingin dicapai oleh sebab itu tidak dapt dipungkiri bahwa bakat dan prestasi saling berkaitan. Bakat (Aptitude) merupakan potensi yang dimilki oleh seseorang sebagai bawaan sejak lahir. Sedangkan prestasi belajar merupakan bukti keberhasilan yang telah dicapai oleh sesorang. Dengan demikian bakat dan prestasi perlu untuk dikembangkan agar keduanya seimbang dapat menjadi tolak ukur pencapaain.

\section{SIMPULAN}

Berdasarkan hasil penelitian maka dapat disimpulkan bahwa terdapat pengaruh Prestasi belajar siswa secara kuat dan positif oleh kemampuan Bakat Numerikal siswa SMA Negeri 4 Ambon. Hal ini berarti Hipotesa H0 ditolak dan Ha diterima artinya semakin baik dan tinggi variabel bakat numerikal maka semakin memiliki pengaruh yang signifikan terhadap prestasi belajar. Kemudian dari persamaan regresi : $\hat{Y}=\beta+$ (b1 .X1) Prestasi belajar $=8,084+(2.549 \mathrm{x} \mathrm{X} 1)$ antara kemampuan numerikal mempunyai pengaruh yang signifikan terhadap prestasi belajar karena mempunyai nilai $\mathrm{T}$ hitung (17.4422) lebih besar dari T tabel (1.699) dengan taraf signifikansi 0.05 .

\section{DAFTAR PUSTAKA}

Ali, M \& Asrori, M. (2005). Psikologi Remaja; Perkembangan Peserta Didik. Jakarta : Bumi Askara.

Gladding T Samuel. (2012). Konseling Profesi yang Menyeluruh. Jakarta: Indeks.

Hukubun, N., Resley I, \& Arjanto, P. (2015). Pemahaman Individu Teknik Tes : Surabaya:Unesa University Press.

Nurihsan. J. A. (2010). Bimbingan dan Konseling dalam berbagai Latar Kehidupan. Bandung : Refika Aditama.

Pusat Bahasa Depatemen Pendidikan Nasional. (200). KBI Indonesia. Jakarta: Balai Pustaka.

Suryabarta, S. (1998). Psikologi Pendidikan. Jakarta : Raja Grafindo Persada.

Sugiyono. (2011). Metode Penilitian Kuantitatif, kualitatif dan $R$ dan D. Bandung : ALFABETA.

Slameto. (2003). Belajar dan Faktor-faktor yang mempengaruhui. Jakarta : Rineka Cipta.

Sukardi Dewa Ketut. (1989). Pendekatan konseling karir di dalam bimbingan karir. Jakarta: Ghalia Indonesia. 